\title{
Association of MTHFR C677T polymorphism with severity and localization of chronic atrophic gastritis patients without Helicobacter pylori infection: a case control study
}

Siya Kong ${ }^{1,2}$, Feng Ye ${ }^{1 *}$, Yini Dang ${ }^{1}$, Yifei Hua ${ }^{1,2}$ and Guoxin Zhang ${ }^{1,2^{*}}$

\begin{abstract}
Background: Previous reports indicate that the methylenetetrahydrofolate reductase (MTHFR) 677 C > T polymorphism plays a role in gastric cancer. However, whether it influences the development and progression of atrophic gastritis remains ambiguous. We aimed to determine the possible relationship between MTHFR C677T polymorphism and the severity of atrophic gastritis.

Methods: A total of 128 patients without Helicobacter pylori infection were included in the study. The severity of gastric atrophy was assessed by pathological diagnosis using OLGA and OLGIM Gastritis Staging System. MTHFR 677C > T genotyping was performed by digital fluorescence molecular hybridization. Categorical variables were analyzed by percentages using the $x^{2}$ test.

Results: In this study, the $\Pi$ genotype was significantly more frequent among Helicobacter pylori-negative patients aged $\leq 44$ years (age $\leq 44$ years vs. $>44$ years, $P=0.039$ ). Patients with $\Pi$ genotype showed a higher ratio of incisura with atrophy or intestinal metaplasia ( $T \mathrm{v}$ s. $C C+C T, P=0.02$ ). Furthermore, $\Pi$ genotype was associated with more severe lesions compared with the $C C+C T$ genotypes ( $T$ vs. $C C+C T$ for atrophy: $P=0.07$; for intestinal metaplasia: $P=0.01$; for moderate-to-severe lesions: $P=0.01$ ). OLGA and OLGIM stages III-IV were observed more frequently in patients with $\Pi$ genotype compared with $C C+C T$ genotypes (for OLGA: $P=0.003$; for OLGIM: $P=0.036$ ).

Conclusions: The MTHFR 677C > T T genotype showed an increased risk of moderate-to-severe lesions by OLGA and OLGIM stages, and these results indicate that MTHFR C677T polymorphism may act as a predictive marker for precancerous gastric lesions, especially in Helicobacter pylori-negative patients aged $\leq 44$ years.
\end{abstract}

Keywords: MTHFR C677T, Polymorphism, Atrophic gastritis, Homocysteine, Incisura

\footnotetext{
* Correspondence: fengye@njmu.edu.cn; guoxinz@njmu.edu.cn

'Department of Gastroenterology, First Affiliated Hospital of Nanjing Medical University, No. 300 Guangzhou Road, Nanjing 210029, China

Full list of author information is available at the end of the article
}

(c) The Author(s). 2020 Open Access This article is licensed under a Creative Commons Attribution 4.0 International License, which permits use, sharing, adaptation, distribution and reproduction in any medium or format, as long as you give appropriate credit to the original author(s) and the source, provide a link to the Creative Commons licence, and indicate if changes were made. The images or other third party material in this article are included in the article's Creative Commons. licence, unless indicated otherwise in a credit line to the material. If material is not included in the article's Creative Commons licence and your intended use is not permitted by statutory regulation or exceeds the permitted use, you will need to obtain permission directly from the copyright holder. To view a copy of this licence, visit http://creativecommons.org/licenses/by/4.0/. The Creative Commons Public Domain Dedication waiver (http://creativecommons.org/publicdomain/zero/1.0/) applies to the data made available in this article, unless otherwise stated in a credit line to the data. 


\section{Background}

Gastric cancer is the third primary cause of cancerrelated death in the world [1]. According to the Correa's theory, a series of precancerous lesions (atrophic gastritis [AG], intestinal metaplasia [IM], and dysplasia) is caused by chronic inflammation of the gastric mucosa, which leads to the evolution of stomach cancer [2]. AG is a chronic disorder losing the oxyntic glands, which is characterized by lamina propria fibrosis or their replacement with pseudo-pyloric or IM [3]. Therefore, early supervision of AG could reduce the incidence of gastric cancer [4].

Cancer development is a result of intricate interactions between genetic and environmental factors. Epigenetic changes like DNA methylation play an important part in cancer development [5]. 5,10-Methylenetetrahydrofolate reductase (MTHFR) has a role in folate metabolism and is associated with DNA, RNA, and protein methylation [6]. MTHFR C677T polymorphism is associated with various tumors, as this change in sequence reduces the activity of this enzyme [6, 7]. Indeed, individuals with the TT and CT genotypes have mildly higher homocysteine levels than $\mathrm{CC}$ homozygotes [8]. In addition, hyperhomocysteinemia is a growing risk for different precancerous lesions according to its observed effects on morbidity and mortality among patients [9, 10]. Previous studies have shown that gastric diseases might cause hyperhomocysteinemia through nutrient malabsorption [11]. As a result, AG patients with TT genotype have a much higher risk of gastric cancer. Therefore, MTHFR C677T polymorphism might be useful in predicting the development and severity of gastrointestinal cancer, especially in Asian populations [12-14]. However, the function of MTHFR C677T polymorphism in stomach precancerous lesions is still unclear. Therefore, based on the risk levels (0-IV) ranked by the Operative Link on Gastritis Assessment (OLGA) and Operative Link on Gastric Intestinal Metaplasia Assessment (OLGIM) grading systems [15], we investigated the relationship between MTHFR C677T polymorphism and AG in Helicobacter pylori-negative patients in this study.

\section{Methods}

\section{Trial design and subjects}

This study was designed as a single-center, cross sectional observational trial. Consecutive patients who underwent endoscopy were recruited in the First Affiliated Hospital of Nanjing Medical University from November 2018 to December 2019. A total of 128 patients suffering from AG were diagnosed for the first time and had not received any previous treatments, and each diagnosis was confirmed after endoscopy by pathological examination. The exclusion criteria were: (1) Helicobacter pylori (H. pylori) positivity (an independent contributing factor to the development of AG); (2) previous eradication treatment of $H$. pylori; (3) use of proton pump inhibitors, antibiotics, or $\mathrm{H}_{2}$-receptor blockers in the previous 6 months; and (4) intake of drugs influencing the level of folic acid. We assessed $H$. pylori infection by the ${ }^{13} \mathrm{C}$-urea breath test (UBT). The study protocol was reviewed and approved by the ethics committee of the First Affiliated Hospital of Nanjing Medical University. We obtained written informed consent from every participant. This trial was completed and registered with ClinicalTrials.gov (ChiCTR1900020815,Chinese Clinical Trial Registry).

\section{Assessment and grading of AG}

All pathological diagnoses were made by histological examination of gastric biopsy samples (corpus, antrum and incisura) following the updated Sydney System [16]. We used $10 \%$ formalin to fix biopsies, and the samples were sectioned and stained by hematoxylin and eosin. Endoscopic atrophy was assessed by the KimuraTakemoto classification [17]. The classification of gastritis was calculated by OLGA and OLGIM staging systems, in which a higher stage number represents a more severe lesion [15]. Two independent pathologists, who were blinded to patient characteristics, assessed the biopsies. The biopsies were assessed by a third pathologist again until agreement was reached to prevent disagreement.

\section{Determination of plasma folic acid, gastrin-17,} homocysteine, pepsinogen I and pepsinogen II levels Blood samples were obtained from 128 patients for the measurement. Gastrin-17, pepsinogen I, and pepsinogen II levels were determined with an ELISA kit. The absorbance of samples was measured at $450 \mathrm{~nm}$. To get serum sample concentrations, assay results were analyzed by GastroSoft 1.51b for Excel (Biohit HealthCare). High-performance liquid chromatography was used to measure levels of homocysteine, and radioimmunoassay was used to measure plasma folic acid levels. In the study, hyperhomocysteinemia level was defined as a concentration more than $15.0 \mu \mathrm{mol} / \mathrm{L}$ and a concentration less than $6.0 \mathrm{ng} / \mathrm{mL}$ was regarded as folate deficiency.

\section{DNA extraction and genotyping of MTHFR polymorphism}

We extracted genomic DNA from blood samples using a column extraction kit (QIAGEN Inc., USA). The DNA content was quantified using a Nanodrop spectrophotometer (BioLab). For MTHFR C677T genotyping, digital fluorescence molecular hybridization (DFMH) was performed using a commercial kit (Sino Era Genotech, Beijing, China) as described previously [18]. The gene polymorphisms were then analyzed with the realtime PCR (Tianlong, Xi'an, China) [19]. 


\section{Statistical analysis}

Categorical variables were analyzed by percentages using $x^{2}$ test. Continuous variables were described by mean values with standard deviations and were compared between groups using Student's t-test. Relationships between the clinical parameters were assessed by Spearman's rank test. The agreement between endoscopic and histological findings regarding the classification of AG was analyzed based on the kappa value. If the $P$-value was less than 0.05 , results were considered significant. Multiple comparisons were made using the binominal logistic regression analysis. The Statistical Package for the Social Sciences (SPSS Inc., USA) software version 25.0 was used for statistical analyses.

\section{Results}

\section{$\pi T$ genotype is more frequent among younger AG patients} without $H$. pylori infection

The study group consisted of 128 AG patients (50.00\% men, age range $27-80$ years, mean age $55.1 \pm 10.2$ years). The clinical characteristics of patients are shown in Table 1. The genotypes and frequencies observed in our population were TT in $21.88 \%$ (28/128) of patients, CT in $53.91 \%$ (69/ $128)$, and CC in $24.22 \%$ (31/128). This distribution followed the Hardy-Weinberg equilibrium $(P=0.817)$. Generally, the allele frequencies of the MTHFR C677T genotypes should be stable for people of all age groups. However, in patients 44 years or younger ( $\leq 44$ years), the frequency of the TT genotype was significantly higher than that in older patients greater than 44 years $(41.18 \%$ vs. $18.92 \%$; $P=0.039$; Fig. 1$)$. For the 17 patients aged 27-44 years, the MTHFR C677T genotypes and frequencies were TT in $41.18 \%$ (7/17), CT in $29.41 \%$ (5/17), and CC in $29.41 \%$ (5/17). In the 111 patients older than 44 years, the genotypes and frequencies were TT in $18.92 \%$ (21/111), CT in $57.66 \%$ (64/111), and CC in $23.42 \%(26 / 111)$. In addition, the pepsinogen I to pepsinogen II ratio (PGR) was significantly higher among patients aged 44 years and older compared to that among patients older than 44 years $(13.0 \pm 4.2$ vs. $10.9 \pm 3.9 ; P=$ 0.045).

The analyzed factors were age; gender; presence of peptic ulcers; smoking and drinking habits; body mass index; Hcy; BMI; family history; MTHFR C677T genotype. The number of each variable or mean $\pm \mathrm{SD}$, odd ratio, 95\% confidence interval, and $P$-value are shown in Table 2. MTHFR C677T genotype and aging remained independent risk factors.

\section{AG may be main cause of hyperhomocysteinemia in AG patients without $H$. pylori infection rather than MTHFR polymorphism}

As shown in Table 3, the mean levels of Hcy in patients with the CC genotype, CT, or TT genotypes were $11.7 \pm$ $5.4 \mu \mathrm{mol} / \mathrm{L}, 12.9 \pm 5.6 \mu \mathrm{mol} / \mathrm{L}$ or $13.5 \pm 6.0 \mu \mathrm{mol} / \mathrm{L}$, respectively. The highest levels of Hcy were observed in patients with TT genotype followed by those with $\mathrm{CT}$ and $\mathrm{CC}$

Table 1 Helicobacter pylori-negative patients characteristics stratified by MTHFR C677T genotypes

\begin{tabular}{|c|c|c|c|c|}
\hline Characteristic & $\begin{array}{l}C C \\
n=31\end{array}$ & $\begin{array}{l}C T \\
n=69\end{array}$ & $\begin{array}{l}\pi \\
n=28\end{array}$ & $P$ Value \\
\hline Age (years), mean $\pm S D$ & $55 \pm 10$ & $56 \pm 9$ & $54 \pm 13$ & N.S \\
\hline $27-44$ & 5 & 5 & 7 & \\
\hline $45-62$ & 17 & 48 & 14 & \\
\hline $63-80$ & 9 & 16 & 7 & \\
\hline Male, n (\%) & $15(48.4 \%)$ & $34(49.3 \%)$ & $15(53.6 \%)$ & N.S \\
\hline Family history of gastric cancer in first-degree relatives, $\mathbf{n}(\%)$ & $7(22.6 \%)$ & $19(27.5 \%)$ & $4(14.3 \%)$ & N.S \\
\hline Smoking status & & & & N.S \\
\hline Never & 23 & 50 & 19 & \\
\hline Current/Former & 8 & 19 & 9 & \\
\hline Alcohol status & & & & N.S \\
\hline Never & 23 & 53 & 19 & \\
\hline Current/Former & 8 & 16 & 9 & \\
\hline Gastrin-17 (pmol/L) & $8.2 \pm 20.6$ & $5.8 \pm 11.4$ & $3.8 \pm 6.6$ & N.S \\
\hline Pepsinogen I ( $\mu \mathrm{g} / \mathrm{L})$ & $104.8 \pm 54.8$ & $103.6 \pm 69.5$ & $81.1 \pm 31.3$ & N.S \\
\hline Pepsinogen II ( $\mu \mathrm{g} / \mathrm{L})$ & $10.5 \pm 6.3$ & $10.1 \pm 8.6$ & $8.4 \pm 3.8$ & N.S \\
\hline PGR & $11.3 \pm 4.7$ & $11.4 \pm 4.0$ & $10.5 \pm 3.4$ & N.S \\
\hline BMI $\left(\mathrm{kg} / \mathrm{m}^{2}\right)$ & $22.4 \pm 2.8$ & $22.3 \pm 2.8$ & $22.6 \pm 2.5$ & N.S \\
\hline
\end{tabular}

CC MTHFR 677CC, CT MTHFR 677CT, TT MTHFR 677TT, SD Standard deviation, PGR Pepsinogen I and pepsinogen II ratio, Hcy Homocysteine, BMI Body mass index, N.S Not significant 
a

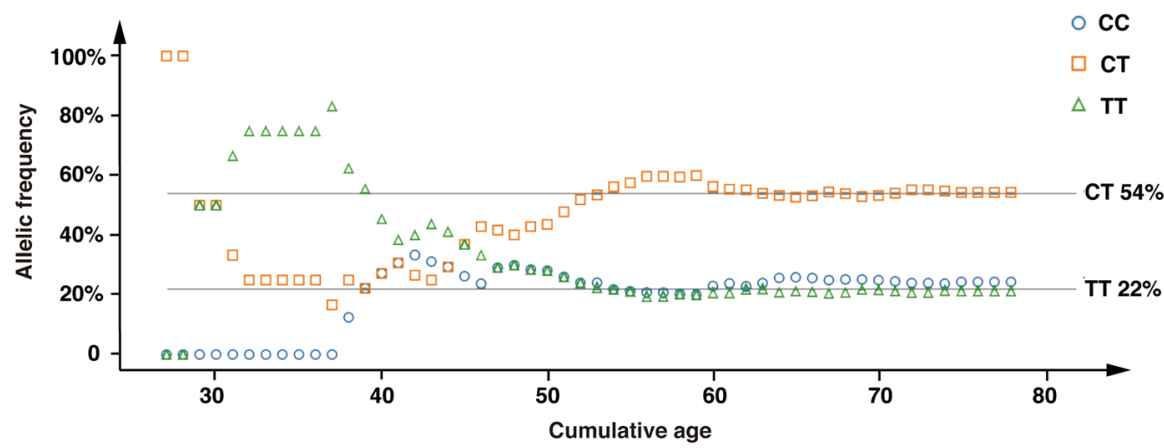

b

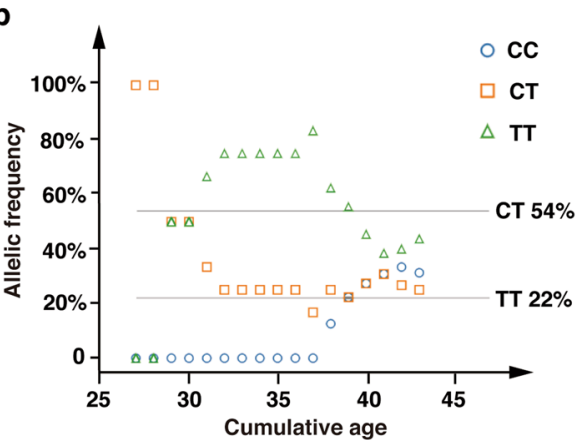

c

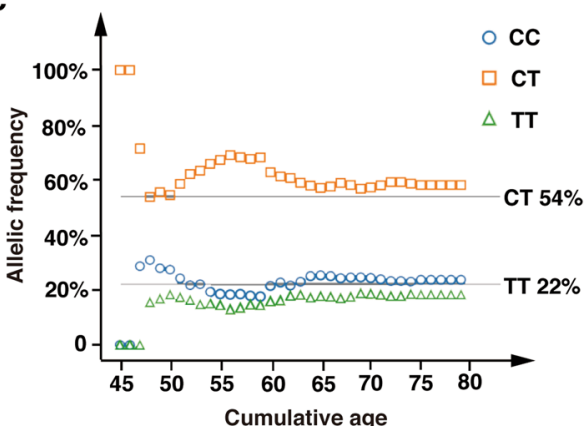

Fig. 1 MTHFR C677T allelic frequency (Y-axis) with respect to cumulative age (X-axis) in different patient age groups. The MTHFR C677T allelic frequency in all Helicobacter pylori-negative patients included in the study. The frequency of the $\Pi$ genotype was significantly higher among patients aged $\leq 44$ years than among patients over 44 years $(41.18 \%$ vs. $18.92 \% ; P=0.039)$. The two horizontal lines represent the genotype frequencies in 128 patients in our study $(T=21.88 \%, C T=53.91 \%)$. b. The MTHFR C677T allelic frequency in patients aged 27-44 years. c. MTHFR C677T allelic frequency in Helicobacter pylori-negative patients aged 45-80 years

genotypes $(P>0.05)$. In addition, no significant difference was observed in the incidence of hyperhomocysteinemia $(>15 \mu \mathrm{mol} / \mathrm{L})$ among patients with the different MTHFR C677T genotypes $(P=0.82)$. However, folic acid deficiency $(\leq 6 \mathrm{ng} / \mathrm{mL}$, as defined in ref. [20]) was observed more often in patients with TT genotype compared with the CT and CC genotypes $(P=0.001)$.
As shown in Table 4, in our population, 29.69\% (38/ 128) of AG patients had hyperhomocysteinemia and $16.41 \%(21 / 128)$ of AG patients had folic acid deficiency. We found that patients with folic acid deficiency had a significantly higher incidence of hyperhomocysteinemia compared with patients without folic acid deficiency (52.38\% [11/21] vs. $25.23 \%$ [27/107], $P=0.013)$.

Table 2 Variables examined for determining the risk of moderate-to-severe lesions

\begin{tabular}{|c|c|c|c|c|c|}
\hline Variables & Number & $P$ Value & OR & $95 \% \mathrm{Cl}$ & $P$ Value \\
\hline Age $(>55 /<55$ year $)$ & $64 / 64$ & 0.04 & 2.28 & $1.04-5.00$ & 0.04 \\
\hline Gender (male/female) & $64 / 64$ & 0.85 & 1.07 & $0.40-2.82$ & 0.90 \\
\hline $\begin{array}{l}\text { Peptic ulcer } \\
\text { (positive/negative) }\end{array}$ & $21 / 107$ & 0.66 & 1.33 & $0.56-2.76$ & 0.59 \\
\hline Smoking (yes/no) & $36 / 92$ & 0.79 & 0.77 & $0.25-2.36$ & 0.65 \\
\hline Drinking (yes/no) & $33 / 95$ & 0.75 & 1.32 & $0.43-4.00$ & 0.63 \\
\hline BMI $\left(\mathrm{kg} / \mathrm{m}^{2}\right)$ & $22.4 \pm 2.7$ & & 1 & $0.86-1.16$ & 0.99 \\
\hline Hcy ( $\mu \mathrm{mol} / \mathrm{L})$ & $12.8 \pm 5.6$ & & 0.98 & $0.91-1.05$ & 0.54 \\
\hline Family history (yes/no) & $30 / 98$ & 0.77 & 1.08 & $0.41-1.45$ & 0.76 \\
\hline MTHFR C677T (CC + CT/TT) & $100 / 28$ & 0.01 & 4.12 & $1.29-13.21$ & 0.02 \\
\hline
\end{tabular}

Hcy Homocysteine, BMI Body mass index, OR Odds ratio, $P$-values were calculated using a binominal logistic regression analysis. $C I$ Confidence interval 
Table 3 Baseline folic acid and Hcy levels in AG patients without Helicobacter pylori infection stratified by MTHFR C677T genotypes

\begin{tabular}{|c|c|c|c|c|}
\hline Characteristic & $\begin{array}{l}C C \\
n=31\end{array}$ & $\begin{array}{l}C T \\
n=69\end{array}$ & $\begin{array}{l}\Pi \pi \\
n=28\end{array}$ & $P$ Value \\
\hline Folic acid (nmol/L) & $42.5 \pm 12.6$ & $36.9 \pm 13.9$ & $32.6 \pm 17.7$ & N.S \\
\hline Hcy ( $\mu \mathrm{mol} / \mathrm{L})$ & $11.7 \pm 5.4$ & $12.9 \pm 5.6$ & $13.5 \pm 6.0$ & N.S \\
\hline \multicolumn{5}{|c|}{ Hyperhomocysteinemia } \\
\hline Yes & $8(25.8 \%)$ & $22(31.9 \%)$ & $8(28.6 \%)$ & N.S \\
\hline No & $23(74.2 \%)$ & $47(68.1 \%)$ & $20(71.4 \%)$ & \\
\hline \multicolumn{5}{|l|}{ Folic acid deficiency } \\
\hline Yes & $1(3.2 \%)$ & $9(13.0 \%)$ & $11(39.3 \%)$ & 0.001 \\
\hline No & $30(96.8 \%)$ & $60(87.0 \%)$ & $17(60.7 \%)$ & \\
\hline
\end{tabular}

N.S Not significant

\section{Association between high-risk OLGA/OLGIM stages III-IV and MTHFR C677T polymorphism}

The results regarding the influence of the MTHFR C677T polymorphism on lesion status in the gastric mucosa of AG patients are presented in Table 5. The antrum region showed the highest frequency of atrophy or IM $(86.72 \%, 111 / 128)$, followed by the incisura $(37.50 \%$, $48 / 128)$ and corpus $(8.59 \%, 11 / 128)$. We found no association between MTHFR C677T polymorphism and lesions in the corpus and antrum $(P>0.05)$. However, in the incisura part of the stomach, patients with TT genotype showed a higher susceptibility to develop lesions including atrophy or IM $(\mathrm{CC}+\mathrm{CT}$ vs. TT: $40.00 \%$ [40/ $100]$ vs. $64.29 \%[18 / 28], P=0.02)$. OLGA and OLGIM stages III-IV were observed more frequently in patients with TT genotype compared with the $\mathrm{CC}+\mathrm{CT}$ genotypes (for OLGA: CC + CT vs. TT: $16.50 \%$ [17/103] vs. $44.00 \%$ [11/25], $P=0.003$; for OLGIM: CC + CT vs. TT: $16.05 \%$ [13/81] vs. $31.91 \%$ [15/47], $P=0.036)$.

For moderate-to-severe lesions (moderate-to-severe IM, moderate-to-severe atrophy or low-grade intraepithelial neoplasia in any one location), TT homozygous patients were at an increased risk compared with $\mathrm{CC}+$ CT patients $(P=0.01)$. In addition, TT homozygous patients had an increased risk of IM at any location compared with $\mathrm{CC}+\mathrm{CT}$ patients $(P=0.01)$. Although not statistically significant $(P=0.07)$, a trend towards a higher frequency of more severe atrophy at any location

Table 4 Association between hyperhomocysteinemia and folic acid deficiency in AG patients without Helicobacter pylori infection

\begin{tabular}{llcll}
\hline & & \multicolumn{4}{c}{ Hyperhomocysteinemia } \\
\cline { 3 - 5 } & & No & Yes & P \\
\hline Folic acid deficiency & No & 80 & 27 & 0.013 \\
& Yes & 10 & 11 & \\
\hline
\end{tabular}

was observed in those with the TT genotype $(\mathrm{CC}+\mathrm{CT}$ vs. TT: $38.00 \%$ vs. $57.14 \%)$.

The MTHFR C677T polymorphism was an independent predictor of the severity of lesions as shown in Table 5 (TT vs. CC + CT for atrophy: odds ratio $[\mathrm{OR}]=$ 2.18; 95\% confidence interval $[\mathrm{CI}], 0.93-5.09 ; P=0.07$; for $\mathrm{IM}: \quad \mathrm{OR}=3.39 ; 95 \% \mathrm{CI}, 1.27-9.06 ; \quad P=0.02$; for moderate-to-severe lesions: $\mathrm{OR}=3.84 ; 95 \% \mathrm{CI}, 1.24-$ $11.90 ; P=0.02$; for OLGA: OR $=3.98$; $95 \% \mathrm{CI}, 1.54-$ 10.23; $P=0.004$; and for OLGIM: OR $=2.45 ; 95 \% \mathrm{CI}$, 1.05-5.76; $P=0.039)$.

\section{Weak correlation between C-1/C-2 of endoscopic atrophy and OLGA stages I-II}

The Kimura-Takemoto classification (C-1, C-2, C-3, O1, O-2 and O-3) has been performed in Eastern countries for the assessment and grading of AG [21]. In our study, the MTHFR C677T polymorphism was an independent predictor of the severity of lesions in patients stratified according to the OLGA and OLGIM systems. However, we found nothing statistically different on the severity of endoscopic gastric atrophy between those with the TT and CT + CC genotypes according to the Kimura-Takemoto endoscopic classification $(P=0.40$, Fig. 2). In our study, according to the Kimura-Takemoto endoscopic classification, $92.59 \%$ patients were $\mathrm{C}-1$ or C-2 and $80.47 \%$ patients of patients stratified according to the OLGA system were stages I-II. Based on these classifications, the strength of agreement between the $\mathrm{C}$ 1 or C-2 levels on endoscopic atrophy and OLGA stages I-II for the histological atrophy was fair, with a kappa value of 0.29 (95\% CI, 0.06-0.50). In addition, correlations of $\mathrm{C}-1$ or $\mathrm{C}-2$ levels on endoscopic atrophy and stages I-II of OLGA were observed (Spearman's rho = $0.31, P=0.014)$.

\section{Discussion}

DNA methylation is a pivotal epigenetic modification that can be altered in precancerous lesions [2]. As MTHFR is the key gene and metabolite in the onecarbon metabolism pathway that contributes to the provision of methyl groups and metabolism of homocysteine [22, 23], the MTHFR C677T polymorphism may be considered as a reliable factor for predicting the prognosis of gastric precancerous lesions [24, 25]. The reduced activity of the MTHFR enzyme resulting from TT mutation has been linked to aberrant DNA or RNA synthesis, repair, and chromosomal damage [6]. This study evaluated the degree of atrophy and IM in different biopsies to examine whether the TT genotype confers an increased risk for developing moderate-to-severe lesions (moderate-to-severe atrophy or IM in any one biopsy) in patients without $H$. pylori infection. In addition, patients with TT genotype were found to be at a higher 
Table 5 Baseline features of lesion status in the gastric mucosa of patients with AG and without Helicobacter pylori infection stratified by MTHFR C677T genotype

\begin{tabular}{|c|c|c|c|c|c|c|c|}
\hline & \multicolumn{4}{|c|}{ Genotypes } & \multicolumn{3}{|c|}{ C allele dominance } \\
\hline & $\begin{array}{l}C C \\
n=31\end{array}$ & $\begin{array}{l}C T \\
n=69\end{array}$ & $\begin{array}{l}T \\
n=28\end{array}$ & $P$ & $\begin{array}{l}C C+C T \\
n=100\end{array}$ & $\begin{array}{l}\pi \\
n=28\end{array}$ & $P$ \\
\hline \multicolumn{8}{|l|}{ Lesions in biopsies } \\
\hline \multicolumn{8}{|l|}{ Incisura } \\
\hline yes & $10(32 \%)$ & $30(43 \%)$ & $18(64 \%)$ & 0.04 & $40(40 \%)$ & $18(64 \%)$ & 0.02 \\
\hline no & $21(68 \%)$ & 39 (57\%) & $10(36 \%)$ & & $60(60 \%)$ & $10(36 \%)$ & \\
\hline \multicolumn{8}{|l|}{ Antrum } \\
\hline yes & $28(90 \%)$ & $62(90 \%)$ & $21(75 \%)$ & 0.15 & 90 (90\%) & $21(75 \%)$ & 0.06 \\
\hline no & $3(10 \%)$ & $7(10 \%)$ & $7(25 \%)$ & & $10(10 \%)$ & $7(25 \%)$ & \\
\hline \multicolumn{8}{|l|}{ Corpus } \\
\hline yes & $1(3 \%)$ & $5(7 \%)$ & $5(18 \%)$ & 0.17 & $6(6 \%)$ & $5(18 \%)$ & 0.22 \\
\hline no & 30 (97\%) & 64 (93\%) & $23(82 \%)$ & & 94 (94\%) & $23(82 \%)$ & \\
\hline \multicolumn{8}{|l|}{ Atrophy } \\
\hline Absent/Mild & 19 (61\%) & $43(62 \%)$ & $12(43 \%)$ & 0.19 & $62(62 \%)$ & $12(43 \%)$ & 0.07 \\
\hline Moderate/Severe & $12(39 \%)$ & $26(38 \%)$ & $16(57 \%)$ & & 38 (38\%) & 16 (57\%) & \\
\hline \multicolumn{8}{|l|}{ IM } \\
\hline Absent/Mild & $14(45 \%)$ & $34(49 \%)$ & $6(21 \%)$ & 0.04 & $48(48 \%)$ & $6(21 \%)$ & 0.01 \\
\hline Moderate/Severe & $17(55 \%)$ & $35(51 \%)$ & $22(79 \%)$ & & $52(52 \%)$ & $22(79 \%)$ & \\
\hline \multicolumn{8}{|c|}{ Moderate-to-severe lesions } \\
\hline Absent/Mild & $11(35 \%)$ & $28(41 \%)$ & $4(14 \%)$ & 0.04 & 39 (39\%) & $4(14 \%)$ & 0.01 \\
\hline Moderate/Severe & $20(65 \%)$ & $41(59 \%)$ & $24(86 \%)$ & & $61(61 \%)$ & $24(86 \%)$ & \\
\hline \multicolumn{8}{|l|}{ OLGA } \\
\hline$|-| \mid$ & $26(84 \%)$ & $60(87 \%)$ & $17(61 \%)$ & 0.119 & $86(86 \%)$ & $17(61 \%)$ & 0.003 \\
\hline III-IV & $5(16 \%)$ & $9(13 \%)$ & $11(39 \%)$ & & $14(17 \%)$ & $11(39 \%)$ & \\
\hline \multicolumn{8}{|l|}{ OLGIM } \\
\hline$|-| \mid$ & $20(65 \%)$ & $48(70 \%)$ & $13(46 \%)$ & 0.162 & $68(68 \%)$ & $13(46 \%)$ & 0.036 \\
\hline III-IV & 11 (35\%) & 21 (30\%) & 15 (54\%) & & 32 (32\%) & 15 (54\%) & \\
\hline
\end{tabular}

Lesions included atrophy or intestinal metaplasia; atrophy: atrophy located in any one biopsy; intestinal metaplasia: intestinal metaplasia located in any one biopsy; moderate-to-severe lesions: moderate to severe intestinal metaplasia, moderate to severe atrophy or low-grade intraepithelial neoplasia in any one location; $\mathrm{Cl}$ : confidence interval

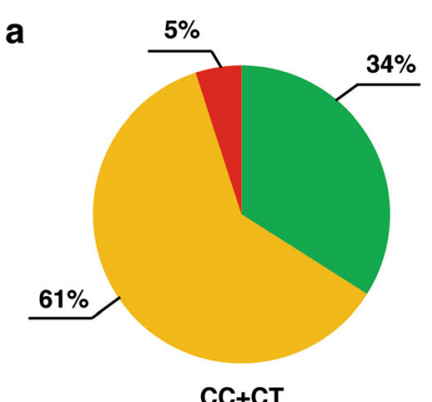

$\mathbf{C C}+\mathbf{C T}$

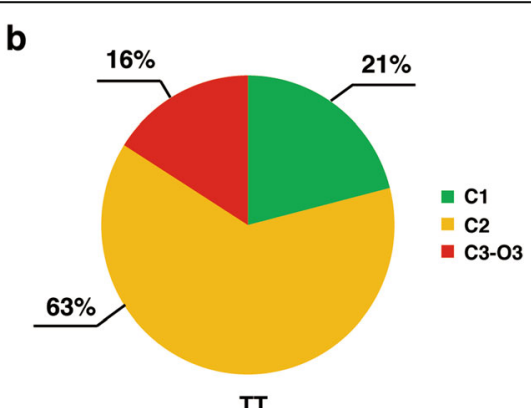

TT

Fig. 2 Distributions of patients with different Kimura-Takemoto endoscopic classifications among different MTHFR C677T genotypes. Helicobacter pylori-negative patients with $\Pi \mathrm{g}$ genotype showed a trend toward a higher frequency of $\mathrm{C}-2$ or $\mathrm{C} 3-\mathrm{O} 3$ lesions according to the Kimura-Takemoto endoscopic classification (CC + CT vs. TT: $66 \%$ vs. $79 \%, P=0.29$ ) 
risk of OLGA and OLGIM stages III-IV compared to patients with the $\mathrm{CC}+\mathrm{CT}$ genotypes. It has been shown previously that OLGA stages I-II are associated with a lower risk while stages III-IV are associated with a higher risk of gastric cancer [26, 27]. Thus, in our study, the TT genotype was a risk factor for gastric precancerous lesions in patients without $H$. pylori infection. It is noteworthy to mention that conflicting results have been reported on the influence of the MTHFR C677T polymorphism on precancerous lesions or cancer. Some studies have shown an increased risk of gastric cancer development among Asians and Caucasians [12, 28], while others studies have reported a negative association $[29,30]$. Conflicting results indicate that populationspecific and geographical factors may account for this phenomenon. For example, the results in our study were based on the study group which included patients who were $H$. pylori negative. However, the study from Itou et al. was based on the study group which included both $H$. pylori negative and positive patients and did not examine the influence from the $H$. pylori infection [31]. In addition, the inconsistent results may be due to the methods of confirming the atrophic gastritis. In previous study, gastric atrophy was only evaluated with serum pepsinogens $(\mathrm{PGI}<70 \mathrm{ng} / \mathrm{dl}$ and $\mathrm{PGI} / \mathrm{II}<3$ ) while all pathological diagnoses were made by histological examination of gastric biopsy samples in our study [31]. It is well established that histological examination is still the gold standard. In studies using histological examination, MTHFR C677T genotypes can monitor stomach cancer risk among atrophic gastritis patients [32].

In addition, we should routinely include the incisura biopsies in sampling protocol for patients with TT genotype for further screening of gastric cancer risk. The incisura is the main lesion for the early-onset of atrophicmetaplastic evolution [33]. It may undergo more severe lesions than the antrum or corpus [34, 35].

A cross-sectional study showed an age-related trend with a growing prevalence of AG in people aged 35-44 years compared to those older than 44 years in Sweden [36]. The morbidity age for AG patients without $H$. pylori infection seems to be younger than previously thought. Previous studies suggested that the growing prevalence of overweight and obese patients resulted in this unexpected trend [36, 37]. In our AG population, we did not find such an association between the severity of AG and overweight or obesity (BMI shown in Table 1, $P>0.05)$. These observations in our study may be due to the fact that we did not establish a control group in the general population for comparison with AG patients, as was done in the study by Song et al. [36]. However, when we divided patients into two age groups (27-44 years and 45-80 years), the frequency of the TT genotype was much higher in the younger age group than in the older age group, indicating that AG patients with TT genotype might have a younger morbidity age and a longer duration of illness. As a result, AG patients with TT genotype may suffer from more severe gastric diseases. Previous studies have confirmed that aging is an independent risk factor for AG progression to gastric cancer [38]. In general population, the prevalence of AG in persons over 40 years is double that in those under 40 years [39]. In our study, however, the frequency of the TT genotype was lower in patients over 44 years of age. This may be due to some important transition of the dominant mechanism. Further research on the difference in MTHFR C677T genotype frequency in these two AG age groups is warranted.

Folate deficiencies may cause uracil misincorporation during DNA synthesis, which increases cancer risk [40]. The data from our study suggest that AG patients with TT genotype have a higher rate of folate deficiency compared with those with the $\mathrm{CC}+\mathrm{CT}$ genotypes $(P=$ 0.001 ), which will theoretically bring a higher rate of hyperhomocysteinemia. However, in our study, this was not the case. No significant difference was observed $(P=$ $0.819)$, indicating that the AG may be more of a direct cause of hyperhomocysteinemia, which is in good agreement with previous research [11]. This phenomenon suggests that the AG factor may play a more important role in the presence of hyperhomocysteinemia than the MTHFR C677Tgenotype. As a result, AG patients are suggested to receive folic acid supplementation to reduce the risk of gastric cancer.

Although not statistically significant, patients with TT genotype in our study showed a trend towards a higher frequency of more severe lesions according to the Kimura-Takemoto endoscopic classification. In addition, some studies have reported that the severity of gastric atrophy assessed by the Kimura-Takemoto endoscopic classification is correlated with OLGA and OLGIM stages [21, 41]. In our study, however, the correlation was weak with a kappa value of 0.29 .

To our knowledge, our study provides the first observation of an association between the MTHFR C677T polymorphism and gastric precancerous lesions in patients without $H$. pylori infection. We suggest that the TT genotype is associated with more severe lesions in $H$. pylori -negative patients. The biopsy of the incisura in AG patients with TT genotype will be useful for further screening of gastric cancer risk, especially for patients younger than 44 years. AG itself may be a contributing factor towards hyperhomocysteinemia. In addition, patients should be cautious about the potential risk of cardiovascular diseases in view of the association between hyperhomocysteinemia and vascular injury [42]. 


\section{Conclusions}

Based on our findings, the effects of the MTHFR C677T polymorphism on gastric precancerous lesions have been systematically examined. We propose that MTHFR C677T genotyping could be useful in identifying Helicobacter pylori-negative patients at increased risk for moderate-to-severe atrophy or IM. Such screening may be valuable clinically in assessing the risk and prognosis of gastric precancerous lesions. In addition, AG patients should receive appropriate folic acid supplementation to prevent hyperhomocysteinemia. Further standardized research including well-designed and strictly implemented trials are required to confirm that the MTHFR C677T genetic polymorphism is an independent predictor of the severity of AG.

\section{Abbreviations}

MTHFR: Methylenetetrahydrofolate reductase; AG: Atrophic gastritis; $\mathrm{H}$. pylori: Helicobacter pylori; IM: Intestinal metaplasia; OLGA: Operative Link on Gastritis Assessment; OLGIM: Operative Link on Gastric Intestinal Metaplasia Assessment; UBT: Urea breath test; Hcy: Homocysteine

\section{Acknowledgements}

The author would like to thank Mr. Zhiwei Li for valuable discussions.

\section{Authors' contributions}

SK, FY, YD, YH, and GZ all contributed to this work. Study concept and design: SK, FY and GZ. Acquisition of data: SK, YD and FY. Analysis and interpretation of data: SK and FY. Drafting of the manuscript: SK. Critical revision of the manuscript for important intellectual content: all authors. Statistical analysis: SK and YH. Figures and tables: SK. Obtained funding: FY and GZ. Study supervision: FY and GZ. All authors had full access to all of the data and approved the final version of this manuscript submitted.

\section{Funding}

This study was supported in part by the National Natural Science Foundation of China (no.81500431, no.81770561, and no.81970499), Natural Science Foundation of Jiangsu Province (no. BK20151039), Six Talent Peaks Project in Jiangsu Province (no.2018-WSW-003), and Jiangsu Province Leading Talents and Innovation Team (CXTDA2017033). The funding body did not have a role in the design of the study or the collection, analysis, and interpretation of data.

\section{Availability of data and materials}

The datasets used and/or analysed during the current study are available from the corresponding author on reasonable request.

\section{Ethics approval and consent to participate}

Its protocol was reviewed and approved by the ethics committee of the First Affiliated Hospital of Nanjing Medical University. This trial was completed and registered with www.chictr.org.cn (ChiCTR1900020815, Chinese Clinical Trial Registry). Participants provided written informed consent.

\section{Consent for publication}

Not applicable.

\section{Competing interests}

The authors declare no conflict of interest.

\section{Author details}

'Department of Gastroenterology, First Affiliated Hospital of Nanjing Medical University, No. 300 Guangzhou Road, Nanjing 210029, China. ${ }^{2}$ First Clinical Medical College of Nanjing Medical University, Nanjing, China.
Received: 1 May 2020 Accepted: 23 July 2020

Published online: 05 August 2020

\section{References}

1. Bray F, Ferlay J, Soerjomataram I, Siegel RL, Torre LA, Jemal A. Global cancer statistics 2018: GLOBOCAN estimates of incidence and mortality worldwide for 36 cancers in 185 countries. CA Cancer J Clin. 2018;68(6):394-424.

2. Dor $\mathrm{Y}, \mathrm{Cedar} \mathrm{H}$. Principles of DNA methylation and their implications for biology and medicine. Lancet. 2018;392(10149):777-86.

3. Hall SN, Appelman HD. Autoimmune Gastritis. Arch Pathol Lab Med. 2019; 143(11):1327-31.

4. Kaji K, Hashiba A, Uotani C, Yamaguchi Y, Ueno T, Ohno K, Takabatake I, Wakabayashi T, Doyama H, Ninomiya I, et al. Correction: grading of atrophic gastritis is useful for risk stratification in endoscopic screening for gastric Cancer. Am J Gastroenterol. 2019;114(5):836.

5. Schubeler D. Function and information content of DNA methylation. Nature. 2015;517(7534):321-6.

6. Coppedè F, Stoccoro A, Tannorella P, Gallo R, Nicoli V, Migliore L. Association of Polymorphisms in Genes Involved in One-Carbon Metabolism with MTHFR Methylation Levels. Int J Mol Sci. 2019;20(15):3754.

7. Yang B, Fan S, Zhi X, Xia R, Wang Y, Zheng Q, Sun G. Geographical and ethnic distribution of MTHFR gene polymorphisms and their associations with diseases among Chinese population. Clin Genet. 2017;92(3):243-58.

8. Hiraoka M, Kagawa Y. Genetic polymorphisms and folate status. Congenital Anomalies. 2017;57(5):142-9.

9. Sun A, Yu-Fong Chang J, Chiang CP. Smart link of chronic atrophic gastritis with atrophic glossitis, gastric parietal cell antibody positivity, vitamin B12 deficiency, and hyperhomocysteinemia. J Formos Med Assoc. 2020;119(5): 1006-7.

10. Hasan T, Arora R, Bansal AK, Bhattacharya R, Sharma GS, Singh LR. Disturbed homocysteine metabolism is associated with cancer. Exp Mol Med. 2019; 51(2):21.

11. Santarelli L, Gabrielli M, Cremonini F, Santoliquido A, Candelli M, Nista EC, Pola P, Gasbarrini G, Gasbarrini A. Atrophic gastritis as a cause of hyperhomocysteinaemia. Aliment Pharmacol Ther. 2004;19(1):107-11.

12. Xia LZ, Liu Y, Xu XZ, Jiang PC, Ma G, Bu XF, Zhang YJ, Yu F, Xu KS, Li H. Methylenetetrahydrofolate reductase C677T and A1298C polymorphisms and gastric cancer susceptibility. World J Gastroenterol. 2014;20(32):11429-38.

13. Xie SZ, Liu ZZ, Yu JH, Liu L, Wang W, Xie DL, Qin JB. Association between the MTHFR C677T polymorphism and risk of cancer: evidence from 446 case-control studies. Tumour Biol. 2015;36(11):8953-72.

14. Chen L, Lu N, Zhang BH, Weng LI, Lu J. Association between the MTHFR C677T polymorphism and gastric cancer susceptibility: a meta-analysis of 5,757 cases and 8,501 controls. Oncol Lett. 2015;10(2):1159-65.

15. Yun CY, Kim N, Lee J, Lee JY, Hwang YJ, Lee HS, Yoon H, Shin CM, Park YS, Kim JW, et al. Usefulness of OLGA and OLGIM system not only for intestinal type but also for diffuse type of gastric cancer, and no interaction among the gastric cancer risk factors. Helicobacter. 2018;23(6):e12542.

16. Dixon MF, Genta RM, Yardley JH, Correa P. Classification and grading of gastritis. The updated Sydney system. International workshop on the histopathology of gastritis, Houston 1994. Am J Surg Pathol. 1996;20(10): 1161-81.

17. Kimura K, Satoh K, Ido K, Taniguchi Y, Takimoto T, Takemoto T. Gastritis in the Japanese stomach. Scand J Gastroenterol Suppl. 1996;214:17-20.

18. Zhang L, Ma X, You G, Zhang X, Fu Q. A novel multiplex HRM assay to detect Clopidogrel resistance. Sci Rep. 2017;7(1):16021.

19. Bai Y, Wu HW, Ma X, Liu Y, Zhang YH. Relationship between UGT1A1*6/*28 gene polymorphisms and the efficacy and toxicity of irinotecan-based chemotherapy. OncoTargets Therapy. 2017;10:3071-81.

20. de Benoist B. Conclusions of a WHO technical consultation on folate and vitamin B12 deficiencies. Food Nutr Bull. 2008;29(2):238-44.

21. Kono S, Gotoda T, Yoshida S, Oda I, Kondo H, Gatta L, Naylor G, Dixon M, Moriyasu F, Axon A. Can endoscopic atrophy predict histological atrophy? Historical study in United Kingdom and Japan. World J Gastroenterol. 2015; 21(46):13113-23.

22. Yan S, Xu D, Wang P, Wang P, Liu C, Hua C, Jiang T, Zhang B, Li Z, Lu L, et al. MTHFR C677T polymorphism contributes to the risk for gastric cancer. Tumour Biol. 2014;35(3):2123-32.

23. Mazzuca F, Borro M, Botticelli A, Aimati L, Gentile G, Capalbo C, Maddalena C, Mazzotti E, Simmaco M, Marchetti P. Effect of MTHFR polymorphisms on gastrointestinal Cancer risk in Italy. World J Oncol. 2015;6(4):394-7. 
24. Boccia S, Hung R, Ricciardi G, Gianfagna F, Ebert MP, Fang JY, Gao CM, Gotze T, Graziano F, Lacasana-Navarro M, et al. Meta- and pooled analyses of the methylenetetrahydrofolate reductase C677T and A1298C polymorphisms and gastric cancer risk: a huge-GSEC review. Am J Epidemiol. 2008;167(5):505-16.

25. Tang M, Wang SQ, Liu BJ, Cao Q, Li BJ, Li PC, Li YF, Qin C, Zhang W. The methylenetetrahydrofolate reductase (MTHFR) C677T polymorphism and tumor risk: evidence from 134 case-control studies. Mol Biol Rep. 2014;41(7): 4659-73.

26. Lahner E, Zagari RM, Zullo A, Di Sabatino A, Meggio A, Cesaro P, Lenti MV, Annibale B, Corazza GR. Chronic atrophic gastritis: natural history, diagnosis and therapeutic management. A position paper by the Italian Society of Hospital Gastroenterologists and Digestive Endoscopists [AIGO], the Italian Society of Digestive Endoscopy [SIED], the Italian Society of Gastroenterology [SIGE], and the Italian Society of Internal Medicine [SIMI]. Dig Liver Dis. 2019;51(12):1621-32.

27. Rugge M, Fassan M, Pizzi M, Farinati F, Sturniolo GC, Plebani M, Graham DY. Operative link for gastritis assessment vs operative link on intestinal metaplasia assessment. World J Gastroenterol. 2011;17(41):4596-601.

28. Lin J, Zeng RM, Li RN, Cao WH. Aberrant DNA methylation of the P16, MGMT, and hMLH1 genes in combination with the methylenetetrahydrofolate reductase C677T genetic polymorphism and folate intake in gastric cancer. Genet Mol Res. 2014;13(1):2060-8.

29. Yoo JY, Kim SY, Hwang JA, Hong SH, Shin A, Choi IJ, Lee YS. Association study between Folate pathway gene single nucleotide polymorphisms and gastric Cancer in Koreans. Genomics Inform. 2012:10(3):184-93.

30. Baroudi O, Benammar-Elgaaied A. Involvement of genetic factors and lifestyle on the occurrence of colorectal and gastric cancer. Crit Rev Oncol Hematol. 2016;107:72-81.

31. Itou S, Goto Y, Kondo T, Nishio K, Kawai S, Ishida Y, Naito M, Hamajima N. No associations of helicobacter pylori infection and gastric atrophy with plasma total homocysteine in Japanese. Int J Med Sci. 2007;4(2):98-104.

32. Palladino M, Chiusolo P, Reddiconto G, Marietti S, De Ritis D, Leone G, Sica S. MTHFR polymorphisms involved in vitamin B12 deficiency associated with atrophic gastritis. Biochem Genet. 2009:47(9-10):645-50

33. Zhang M, Liu S, Hu Y, Bao HB, Meng LN, Wang XT, Xu Y, Zhao J, Lu B. Biopsy strategies for endoscopic screening of pre-malignant gastric lesions. Sci Rep. 2019;9(1):14909.

34. Varbanova M, Wex T, Jechorek D, Rohl FW, Langner C, Selgrad M, Malfertheiner P. Impact of the angulus biopsy for the detection of gastric preneoplastic conditions and gastric cancer risk assessment. J Clin Pathol. 2016;69(1):19-25.

35. Isajevs S, Liepniece-Karele I, Janciauskas D, Moisejevs G, Funka K, Kikuste I, Vanags A, Tolmanis I, Leja M. The effect of incisura angularis biopsy sampling on the assessment of gastritis stage. Eur J Gastroenterol Hepatol. 2014:26(5):510-3.

36. Song H, Held M, Sandin S, Rautelin H, Eliasson M, Soderberg S, Hallmans G, Engstrand L, Nyren O, Ye W. Increase in the prevalence of atrophic gastritis among adults age 35 to 44 years old in northern Sweden between 1990 and 2009. Clin Gastroenterol Hepatol. 2015;13(9):1592-600.

37. Hirabayashi M, Inoue M, Sawada N, Saito E, Abe SK, Hidaka A, Iwasaki M, Yamaji T, Shimazu T, Shibuya K, et al. Effect of body-mass index on the risk of gastric cancer: a population-based cohort study in a Japanese population. Cancer Epidemiol. 2019;63:101622.

38. Sonnenberg A, Genta RM. Changes in the gastric mucosa with aging. Clin Gastroenterol Hepatol. 2015;13(13):2276-81.

39. de Vries AC, Meijer GA, Looman CW, Casparie MK, Hansen BE, van Grieken NC, Kuipers EJ. Epidemiological trends of pre-malignant gastric lesions: a long-term nationwide study in the Netherlands. Gut. 2007:56(12):1665-70.

40. Kim YI. Folate and cancer: a tale of Dr. Jekyll and Mr. Hyde? Am J Clin Nutr. 2018:107(2):139-42.

41. Quach DT, Hiyama T, Le HM, Nguyen TS, Gotoda T. Use of endoscopic assessment of gastric atrophy for gastric cancer risk stratification to reduce the need for gastric mapping. Scand J Gastroenterol. 2020;55(4):402-7.

42. Fu $Y$, Wang $X$, Kong W. Hyperhomocysteinaemia and vascular injury: advances in mechanisms and drug targets. Br J Pharmacol. 2018;175(8): 1173-89.

\section{Publisher's Note}

Springer Nature remains neutral with regard to jurisdictional claims in published maps and institutional affiliations.

Ready to submit your research? Choose BMC and benefit from:

- fast, convenient online submission

- thorough peer review by experienced researchers in your field

- rapid publication on acceptance

- support for research data, including large and complex data types

- gold Open Access which fosters wider collaboration and increased citations

- maximum visibility for your research: over $100 \mathrm{M}$ website views per year

At BMC, research is always in progress.

Learn more biomedcentral.com/submissions 